\title{
P38 MAPK and glucocorticoid receptor crosstalk in bronchial epithelial cells
}

\author{
Simon Lea ${ }^{1}$ (D) Jian Li ${ }^{1} \cdot$ Jonathan Plumb ${ }^{1} \cdot$ Kate Gaffey $^{1} \cdot$ Sarah Mason $^{1} \cdot$ Rosie Gaskell $^{1} \cdot$ Chris Harbron $^{2} \cdot$ \\ Dave Singh ${ }^{1}$
}

Received: 12 July 2019 / Revised: 6 December 2019 / Accepted: 6 January 2020 / Published online: 23 January 2020

(C) The Author(s) 2020

\begin{abstract}
p38 MAPK inhibition may have additive and synergistic anti-inflammatory effects when used with corticosteroids. We investigated crosstalk between p38 MAPK inhibitors and corticosteroids in bronchial epithelial cells to investigate synergistic effects on cytokine production and the molecular mechanisms involved. Effects of the p38 MAPK inhibitor BIRB-796 and dexamethasone alone and in combination on LPS, polyI:C or TNF $\alpha$-induced IL-6, CXCL8 and RANTES were assessed in 16HBEs (human epithelial cell line) and on TNF $\alpha$-induced IL-6 and CXCL8 in primary human epithelial cells from asthma patients and healthy controls. 16HBEs were used to assess effects of BIRB-796 alone and in combination with dexamethasone on glucocorticoid receptor (GR) activity by reporter gene assay, expression of GR target genes and nuclear localisation using Western blot. The effects of BIRB-796 on TNF $\alpha$ stimulated phosphorylation of p38 MAPK and GR at serine (S) 226 by Western blot. Epithelial levels of phosphorylated p38 MAPK and GR S226 were determined by immunohistochemistry in bronchial biopsies from asthma patients and healthy controls. BIRB-796 in combination with dexamethasone increased inhibition of cytokine production in a synergistic manner. Combination treatment significantly increased GR nuclear localisation compared to dexamethasone alone. BIRB-796 inhibited TNF $\alpha$-induced p38 MAPK and GR S226 phosphorylation. Phosphorylated GR S226 and p38 MAPK levels were increased in bronchial epithelium of more severe asthma patients. Molecular crosstalk exists between p38 MAPK activation and GR function in human bronchial epithelial cells, which alters GR activity. Combining a p38 MAPK inhibitor and a corticosteroid may demonstrate therapeutic potential in severe asthma.
\end{abstract}

\section{Key messages}

- Combination of corticosteroid and p38 inhibitor in human bronchial epithelial cells

- Combination increased cytokine inhibition synergistically and nuclear GR

- p38 MAPK inhibition reduced TNF $\alpha$-induced phosphorylation of GR at S226 but not S211

- Phosphorylated GRS226 and p38 is increased in bronchial epithelium in severe asthma

- Combining a p38 inhibitor and a corticosteroid may be effective in asthma treatment

Keywords Corticosteroid insensitivity $\cdot$ Glucocorticoid receptor $\cdot$ p38 MAPK $\cdot$ Asthma $\cdot$ Aronchial epithelial cells

Electronic supplementary material The online version of this article (https://doi.org/10.1007/s00109-020-01873-3) contains supplementary material, which is available to authorized users.

Simon Lea

simon.lea@manchester.ac.uk

1 University of Manchester, NIHR Translational Research Facility, University Hospital of South Manchester, Manchester M23 9LT, UK

2 Roche Pharmaceuticals, 6 Falcon Way, Welwyn Garden City AL7 1TW, UK

$\begin{array}{ll}\text { Abbreviations } \\ \text { ANOVA } & \text { Analysis of variance } \\ \text { ACQ } & \text { Asthma control questionnaire } \\ \text { CXCL } & \text { The chemokine (C-X-C motif) ligand } \\ \text { DUSP1 } & \text { Dual-specificity phosphatase-1 } \\ \text { ELISA } & \text { Enzyme-linked immunosorbent assays } \\ \text { ERK } & \text { Extracellular-regulated kinase } \\ \text { FEV } & \text { Forced expiratory volume in 1 s } \\ \text { FKBP5 } & \text { FK506-binding protein 51 } \\ \text { GILZ } & \text { Glucocorticoid-induced leucine zipper } \\ \text { GINA } & \text { Global Initiative for Asthma }\end{array}$




$\begin{array}{ll}\text { GR } & \text { Glucocorticoid receptor } \\ \text { HNS } & \text { Healthy never smoker controls } \\ \text { HBEC } & \text { Human bronchial epithelial cell } \\ \text { ICS } & \text { Inhaled corticosteroids } \\ \text { IL } & \text { Interleukin } \\ \text { IR } & \text { Interaction ratio } \\ \text { IRF1 } & \text { Interferon regulatory factor 1 } \\ \text { JNK } & \text { c-Jun N-terminal kinase } \\ \text { LPS } & \text { Lipopolysaccharide } \\ \text { MAPK } & \text { Mitogen-activated protein kinases } \\ \text { MEME } & \text { Minimal Essential Medium Eagle } \\ \text { NTHi } & \text { Nontypeable Haemophilus influenzae } \\ \text { PBMCs } & \text { Peripheral blood mononuclear cells } \\ \text { poly I:C } & \text { Polyinosinic:polycytidylic acid } \\ \text { RANTES } & \text { Regulated on Activation, Normal T } \\ & \text { Cell Expressed and Secreted } \\ \text { S } & \text { Serine } \\ \text { TNF } \alpha & \text { Tumour necrosis factor }\end{array}$

\section{Introduction}

Inhaled corticosteroids (ICS) are the mainstay of antiinflammatory treatment for asthma. However, many asthma patients treated with ICS have suboptimal asthma control [1], highlighting the need for novel anti-inflammatory treatments.

The glucocorticoid receptor (GR) is a ligand-dependent transcription factor that resides in the cytoplasm until ligand binding causes nuclear translocation, resulting in transrepression or transactivation of gene transcription [2]. There are numerous phosphorylation sites within the GR Nterminus, changes in which can lead to the alterations of GR function through ligand binding, nuclear localisation, modulating interactions with co-regulators or transcriptional activation [3, 4]. Two such phosphorylation sites are serine (S) 211 and S226 which have roles in subcellular localisation [3]; GRligand nuclear translocation is associated with phosphorylation of S211, while GR nuclear export is associated with S226 phosphorylation.

p38 mitogen-activated protein kinase (MAPK) signalling promotes the secretion of inflammatory proteins through transcription factor activation [5], post-transcriptional mRNA stabilization and enhancement of protein translation $[6,7]$. p38 MAPK inhibitors suppress the inflammatory responses of various cell types within the lung, including alveolar macrophages, lung lymphocytes, airway smooth muscle cells and bronchial epithelial cells [8-10]. Combining p38 MAPK inhibitors and corticosteroids results in additive anti-inflammatory effects in these cell models, due to the different mechanisms of action [8, 11]. Furthermore, these studies have also shown some evidence that the combination effects are more than additive, with a synergistic interaction observed $[8,11]$. p38 MAPK can phosphorylate GR serine residues, altering ligand affinity and transcriptional activity [12-14]. It has been reported that $\mathrm{p} 38$ MAPK activation reduces S211 phosphorylation $[15,16]$, thereby decreasing GR activity. However, p38 MAPK regulation of GR phosphorylation is cell specific, as the effect on S211 phosphorylation is not present in all cell models [17, 18]. Peripheral blood mononuclear cells (PBMCs) from severe asthma patients show a reduction of nuclear GR, which is associated with increased GR S226 phosphorylation [19]. A possible mechanism for the synergistic interaction between p38 MAPK inhibitors and corticosteroids is via regulation of either GR S211 or S226 phosphorylation to enhance GR nuclear localisation.

Epithelial cells play a central role in the pathophysiology of asthma through the release of pro-inflammatory mediators in response to environmental triggers such as infection or stimulation with cytokines [20]. p38 MAPK activation is increased in alveolar macrophages, airway epithelial cells and airway smooth muscle cells of severe asthma patients compared with controls [21-23]. p38 MAPK inhibition of the inflammatory responses of epithelial cells in severe asthma may have therapeutic potential, particularly if there is a synergistic interaction with corticosteroids.

The aim of this study was to investigate crosstalk between p38 MAPK inhibitors and corticosteroids in bronchial epithelial cells. We used a human bronchial epithelial cell (HBEC) line to investigate whether the anti-inflammatory interactions between these drug classes on cytokine production were additive or synergistic. We also investigated whether p38 MAPK inhibition altered GR function by measuring GR activity, nuclear localisation and phosphorylation. Additionally, we used lung samples from asthma patients and healthy controls to study the combination anti-inflammatory effects of these drugs on bronchial epithelial cells, and to perform immunohistochemical analysis of bronchial epithelial cells to further investigate the relationship between p38 MAPK activation and GR phosphorylation.

\section{Methods}

\section{Human bronchial epithelial cell culture}

The human bronchial epithelial cell line $16 \mathrm{HBE} 14 \mathrm{o}^{-}$(ATCC; HBEC) was maintained in supplemented Minimal Essential Medium Eagle (MEME, Gibco, Fisher Scientific UK Ltd., Loughborough, UK). Confluent cells were grown in tissue culture plates until confluent and then incubated in fresh supplemented media in the presence of either lipopolysaccharide ( L P S ) ( $1 \mu \mathrm{g} / \mathrm{ml}, \quad \mathrm{S}$ igma, Poole, UK), polyinosinic:polycytidylic acid (poly I:C) $(100 \mu \mathrm{g} / \mathrm{ml}$, Source Bioscience, Nottingham, UK) or tumour necrosis factor $(\mathrm{TNF} \alpha)(10 \mathrm{ng} / \mathrm{ml}$, Peprotech, London, UK). Cells were 
pre-incubated with dexamethasone $(0.1-1000 \mathrm{nM}$, Sigma) and/or the p38 MAPK inhibitor BIRB-796 (0.1-1000 nM, Sigma) and incubated in $5 \% \mathrm{CO}_{2}$ at $37{ }^{\circ} \mathrm{C}$ for varying time points. Plates were centrifuged at $2000 \mathrm{rpm}$ for $10 \mathrm{~min}$ at $4^{\circ} \mathrm{C}$ and cell-free supernatants removed and stored at $-80^{\circ} \mathrm{C}$ for cytokine analysis.

To assess the effects of LPS, poly I:C and TNF $\alpha$ stimulation on phosphorylated p38 MAPK expression, HBECs were stimulated with LPS $(1 \mu \mathrm{g} / \mathrm{ml})$ or poly I:C $(100 \mu \mathrm{g} / \mathrm{ml})$ for 0 $180 \mathrm{~min}$ or with TNF $\alpha(10 \mathrm{ng} / \mathrm{ml})$ for $0-60 \mathrm{~min}$.

To assess the effects of dexamethasone and BIRB-796 on stimulated phosphorylated p38 MAPK expression, HBECs were pre-incubated for $60 \mathrm{~min}$ with either dexamethasone $(1000 \mathrm{nM})$, BIRB-796 alone $(1000 \mathrm{nM})$ or both in combination, followed by stimulation with LPS $(1 \mu \mathrm{g} / \mathrm{ml})$ or poly I:C $(100 \mu \mathrm{g} / \mathrm{ml})$ for $60 \mathrm{~min}$ or with $\mathrm{TNF} \alpha(10 \mathrm{ng} / \mathrm{ml})$ for $15 \mathrm{~min}$ (based on preliminary time course experiments; Fig. S1).

To assess the effects of dexamethasone and BIRB-796 on GR target gene expression, HBECs were cultured with or without TNF $\alpha(10 \mathrm{ng} / \mathrm{ml})$ for $15 \mathrm{~min}$ followed by dexamethasone $(100 \mathrm{nM})$ and BIRB-796 $(100 \mathrm{nM})$ both alone and in combination for $4 \mathrm{~h}$.

To investigate the effects of dexamethasone on GR phosphorylation at S211 and S226 residues, HBECs were incubated with dexamethasone $(1000 \mathrm{nM})$ or left untreated for 15 $180 \mathrm{~min}$.

To assess whether TNF $\alpha$-induced phosphorylation of GR S226 is p38 MAPK-dependent, HBECs were stimulated with $\mathrm{TNF} \alpha(10 \mathrm{ng} / \mathrm{ml})$ for $15-180 \mathrm{~min}$ with and without preincubation of BIRB-796 (1000 nM) for $60 \mathrm{~min}$.

\section{Study subjects}

Patients with a diagnosis of asthma $(n=23)$ and healthy control subjects $(n=15)$ were recruited; all subjects were required to be lifelong non-smokers. Patients performed spirometry for measurement of forced expiratory volume in $1 \mathrm{~s}\left(\mathrm{FEV}_{1}\right)$ and reversibility to inhaled salbutamol $(200 \mu \mathrm{g})$, asthma control questionnaire (ACQ), and skin prick testing using house dust mite, cat and grass allergens (Soluprick SQ, Alk Abelló (UK) Ltd). The study was approved by the local research ethics committee (NRES Committee North West - Greater Manchester South; REC Ref: 06/Q1403/156). All subjects provided written informed consent.

\section{Bronchoscopy}

Patients with differing asthma severity as defined by the Global Initiative for Asthma (GINA) score (GINA 1, $n=5$; GINA 2, $n=7$; and GINA 3/4, n=6) and healthy control subjects $(n=10)$ underwent bronchoscopy to obtain bronchial biopsies from the lower lobes; these were formalin-fixed and paraffin-embedded as previously described [24]. Asthma patients $(n=5)$ and healthy control subjects $(\mathrm{n}=5)$ underwent bronchoscopy to obtain brushings from the lower lobe segmental airways.

\section{Primary epithelial cell culture}

Bronchial epithelial cells obtained from asthma patients and healthy controls were gently removed from the airway by brushing with a cytology brush (width $5 \mathrm{~mm}$, length $10 \mathrm{~mm}$ ) (Olympus, Southend-on-sea, UK) across the surface of the airway wall. Cells were then placed into fully supplemented BEBM Media (BEBM bulletkit Lonza, Slough, UK) on ice by passing the sheath over the head of the brush to dislodge cells. Cells were centrifuged $\left(400 \mathrm{~g}, 10 \mathrm{~min}, 4^{\circ} \mathrm{C}\right)$ before resuspending into supplemented BEBM media. The whole cell suspension was seeded into collagen-coated (Nutacon, Leimuiden, Netherlands) flasks. Cells were left to adhere and grow and media was replaced twice weekly. When confluent, cells were passaged and plated out into 96-well plates. When $80 \%$ confluence was reached, cells were pre-incubated for $60 \mathrm{~min}$ with either dexamethasone $(100 \mathrm{nM})$, BIRB-796 $(100 \mathrm{nM})$ or both drugs in combination before stimulation with $\mathrm{TNF} \alpha(10 \mathrm{ng} / \mathrm{ml})$ for $24 \mathrm{~h}$.

\section{Cytokine measurements}

Enzyme-linked immunosorbent assays (ELISA) were used to determine the supernatant level of Interleukin (IL)-6, The chemokine (C-X-C motif) ligand 8 (CXCL8), and Regulated on Activation, Normal $\mathrm{T}$ Cell Expressed and Secreted (RANTES) according to the manufacturer's instructions (R\&D Systems, Abingdon, UK). Lower limits of quantification were $32.5 \mathrm{pg} / \mathrm{ml}$ for CXCL8 and RANTES and $9.375 \mathrm{pg} /$ $\mathrm{ml}$ for IL-6.

\section{Western blot}

Western blot analysis was performed using the following antibodies: phospho-p38 MAPK (New England Biolabs, Hitchin, UK), total p38 MAPK (New England Biolabs), phospho-GR S226 (Abcam, Cambridge, UK), phospho-GR S211 (New England Biolabs), total GR (BD bioscience), $\beta$ actin (Abcam) and histone-3 (Cell Signalling Technology, MA, USA) (for full details, see the online supplement). All Western blot protein molecular weights are shown in Fig. S2a. HBECs were lysed for either whole cell lysate or cellular fractions (see online supplement). Nuclear and cytoplasmic fractions were confirmed by the presence of nuclear protein histone- 3 and cytoplasmic protein $\beta$-actin, respectively. The absence of histone- 3 in the cytoplasmic fractions and absence of $\beta$-actin in nuclear fractions were confirmed in $n=5$ separate cultures (Fig. S2b). 


\section{GR- reporter gene assay}

16HBE14o- cells were stably transfected with pGL44.36[luc2P/MMTV/Hygro] vector (Promega) (Sall linearized) using FuGENE6 (Roche, Germany) (as described in online supplement).

Cells with luciferase reporters were treated with dexamethasone, BIRB-796, SB239063, budesonide and TNF $\alpha$, either individually or in combination. Bioluminescence signals were analysed in BRASS software and RAP algorithm. Data were presented as photon counts per minute (cpm).

\section{GR target gene PCR}

RNA was obtained as described in the online supplement. Gene expression was analysed using TaqMan gene expression assays for GLIZ, FKBP5 and the endogenous control glyceraldehyde-3-phosphate dehydrogenase (GAPDH). Relative expression levels compared to unstimulated controls were determined using the $2^{-\Delta \Delta \mathrm{Ct}}$ method. Full details are described in online supplement.

\section{Immunohistochemistry}

Bronchial biopsies were stained with rabbit antihuman GR S226 (Abcam, Cambridge, UK) and rabbit antihuman phosphorylated p38 MAPK (Cell Signalling Technology) coupled with an ImmPRESS ${ }^{\mathrm{TM}}$ Excel Amplified HRP Polymer Staining Kit (Anti-Rabbit IgG) with 3,3' diaminobenzidine as a substrate (Vector Laboratories, CA, USA). Sections were counterstained in Gills haematoxylin (for full details, see the online supplement).

Images were captured using a Nikon Eclipse 80i microscope (Nikon UK Ltd) with an attached QImaging digital camera (Media Cybernetics, MD, USA). Percentages of GR S226- and phosphorylated p38 MAPK-positive epithelial cells were calculated.

\section{Data analysis}

The data and statistical analyses comply with the recommendations on experimental design and analysis in pharmacology [25].

One-way analysis of variance (ANOVA) followed by Tukey-Kramer multiple comparisons tests was used for ELISA and immunohistochemistry data to compare between conditions and subject groups. Pearson's rank was used to assess correlations between phosphorylated p38 MAPK and GR S226 expression. Repeated measures ANOVA with Dunnett multiple comparisons post-test were used to analyse immunofluorescence and Western blot analysis. Maximal inhibition was defined as the effect of the drug at the highest concentration. $\mathrm{IC}_{50}$ values were determined using a four- parameter non-linear iterative curve fitting analysis. A dosesparing analysis to assess whether equivalent responses can be achieved at lower doses of compound than expected given the monotherapy responses and an efficacy-enhancing analysis to assess whether the combination results in a significantly greater maximal effect than either compound as monotherapies were performed [26] and described in full in the online supplement. To assess whether combination treatment in primary epithelial experiments had an additive or synergistic effect, an interaction ratio (IR) was calculated based on observed and expected inhibitions [27]. All statistical analysis was performed in GraphPad Prism (GraphPad Software, http://www. graphpad.com). $P<0.05$ was considered significant.

\section{Results}

\section{Inhibition of cytokine production from HBECs}

The stimulation of HBECs by LPS, poly I:C and TNF $\alpha$ significantly increased secretion of IL-6, CXCL8 and RANTES; $(p<0.05$ for all comparisons of stimulated against unstimulated levels; Fig. S3). LPS-, poly I:C- and TNF $\alpha$ stimulated cytokine secretion was significantly reduced by dexamethasone or BIRB-796 in a concentration-dependent manner (Fig. S3). Differences in the magnitude of maximal inhibition (i.e., inhibition at $1000 \mathrm{nM}$ ) between cytokines were observed. For example, the maximal inhibition of LPSand TNF $\alpha$-stimulated IL- 6 production was greater than RANTES and CXCL 8 secretion $(p<0.05$ for all comparisons; described further in the online supplement and in Table S1). The maximal inhibition caused by BIRB-796 and dexamethasone was generally similar, with any differences described online (Table S1).

Using BIRB-796 in combination with dexamethasone generally provided greater inhibition of LPS-, poly I:C- or TNF $\alpha$ induced cytokine production compared with either drug alone (Fig. 1a-i. The maximum inhibition of cytokine production using the highest concentration of dexamethasone in combination with BIRB-796 was significantly greater compared to either drug alone for many experimental conditions (analysis presented in Table S2).

Figure 2a shows dose-sparing analysis to assess whether equivalent responses can be achieved at lower doses of compound than expected given the monotherapy responses. A dose-sparing combination index where the entirety of the 95\% confidence interval lies below one (Fig. 2a) indicates a significant synergistic effect. Figure $2 b$ shows an efficacyenhancing analysis to assess whether the combination results in a significantly greater maximal effect than either compound as monotherapies. An efficacy-enhancing benefit where the entirety of the $95 \%$ confidence interval lies above zero (Fig. 2b) indicates a significant synergistic effect. A 

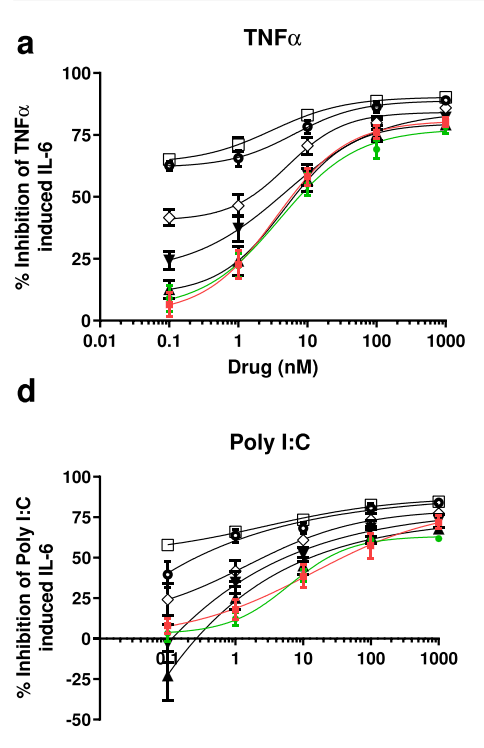

Drug (nM)

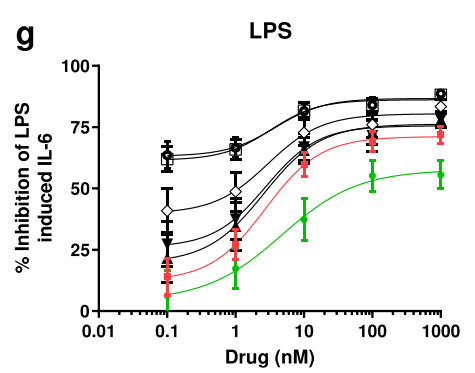

Fig. 1 Combination effect of dexamethasone and BIRB-796 on LPS-, poly I:C- or TNF $\alpha$-induced cytokines in human bronchial epithelial cells. $16 \mathrm{HBE} 14 \mathrm{o}-$ cells were pre-treated with dexamethasone $(0.1-1000 \mathrm{nM})$, BIRB-796 (0.1-1000 nM) either alone or in combination at all concentrations or with vehicle (DMSO $0.05 \%$ ) for $1 \mathrm{~h}$ before $24 \mathrm{~h}$ stimulation with either TNF $\alpha(10 \mathrm{ng} / \mathrm{ml})(\mathbf{a}-\mathbf{c})$, poly I:C (100 $\mu \mathrm{g} / \mathrm{ml})(\mathbf{d}-\mathbf{e})$ or LPS

combination treatment showed a significant synergistic dosesparing effect on LPS-induced IL-6, poly I:C-induced CXCL8 and RANTES and TNF $\alpha$-induced CXCL8. There was a significant synergistic efficacy-enhancing benefit for LPSinduced IL- 6 and RANTES and TNF $\alpha$-induced IL- 6 and CXCL8.

We next investigated whether these synergistic effects were due to p38 MAPK modulation of glucocorticoid receptor activity. Therefore, we investigated the effects of p38 MAPK inhibition on GR activity, cellular location and phosphorylation status.

\section{Effects of p38 MAPK inhibition on corticosteroid-induced GR reporter activity}

Dexamethasone (1-100 nM) and budesonide (1-100 nM) significantly induced GR-reporter activity above the untreated controls $(p<0.05)$ (Fig. 3a-c and Fig. S4, respectively). There was no effect of BIRB-796 in combination with either corticosteroid except for budesonide $1 \mathrm{nM}$ combined with
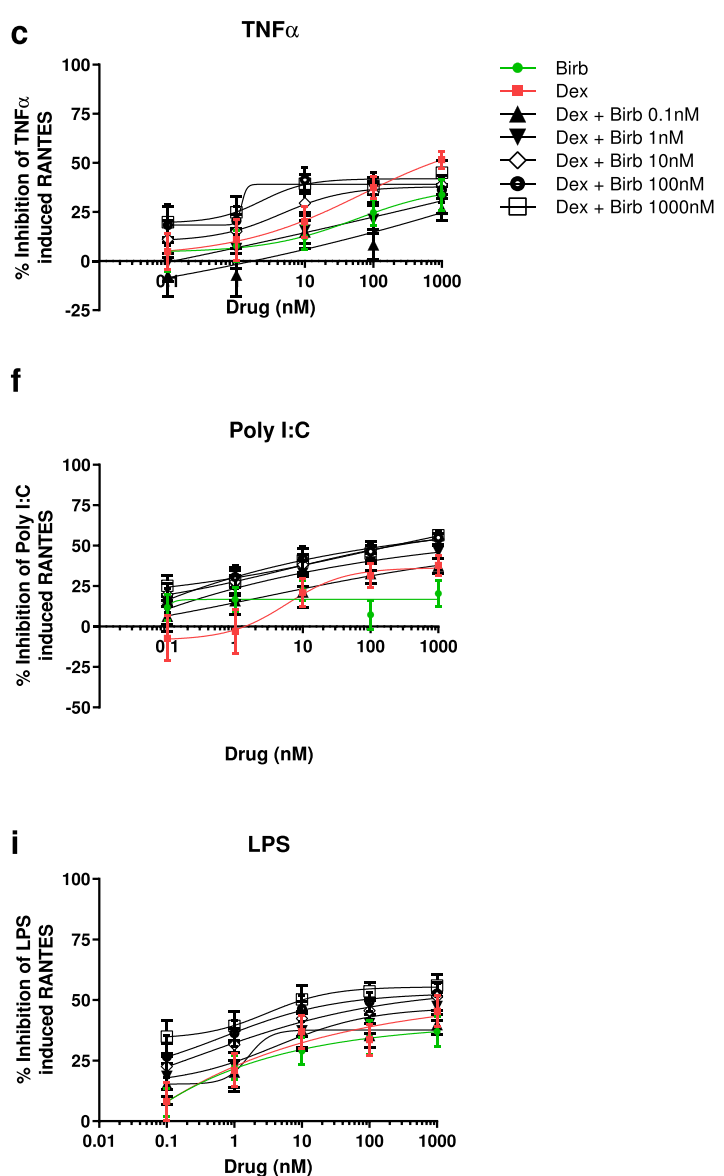

$(1 \mu \mathrm{g} / \mathrm{ml})(\mathbf{g}-\mathbf{i})$. Supernatants were collected and assayed for IL-6 (a, $\mathbf{d}$ and $\mathbf{g})$, CXCL8 (b, e and $\mathbf{h}$ ) or RANTES (c, $\mathbf{f}$ and $\mathbf{i})$ release by ELISA ( $n=12$ separate cultures). Data presented as mean \pm SEM percentage inhibition of -induced IL-6, CXCL8 or RANTES. Lines represent four-parameter non-linear dose response curves

BIRB-796 (1000 nM) which significantly increased GRreporter activity above budesonide alone $(p<0.05)$ (Fig. 3e). SB239063 (1000 nM) had no effect in combination with dexamethasone (Fig. S4).

$\mathrm{TNF} \alpha(10 \mathrm{ng} / \mathrm{ml})$ stimulation caused a small increase in GR-reporter activity. Dexamethasone (1-100 nM) and budesonide $(1-100 \mathrm{nM})$ caused large increases in GRreporter activity in TNF $\alpha$-stimulated cells $(p<0.05$ for all comparisons), with the addition of BIRB-796 or SB239063 causing further significant upregulation of GR-reporter activity compared to corticosteroid alone $(\mathrm{p}<0.05$ for all comparisons).

\section{Effects of p38 MAPK inhibition on corticosteroid-induced GR target genes}

To determine if increased GR activity observed translated to increased induction of GR target genes, the effects of combination treatment of BIRB-796 and dexamethasone on GILZ and FKBP5 were assessed. 
a

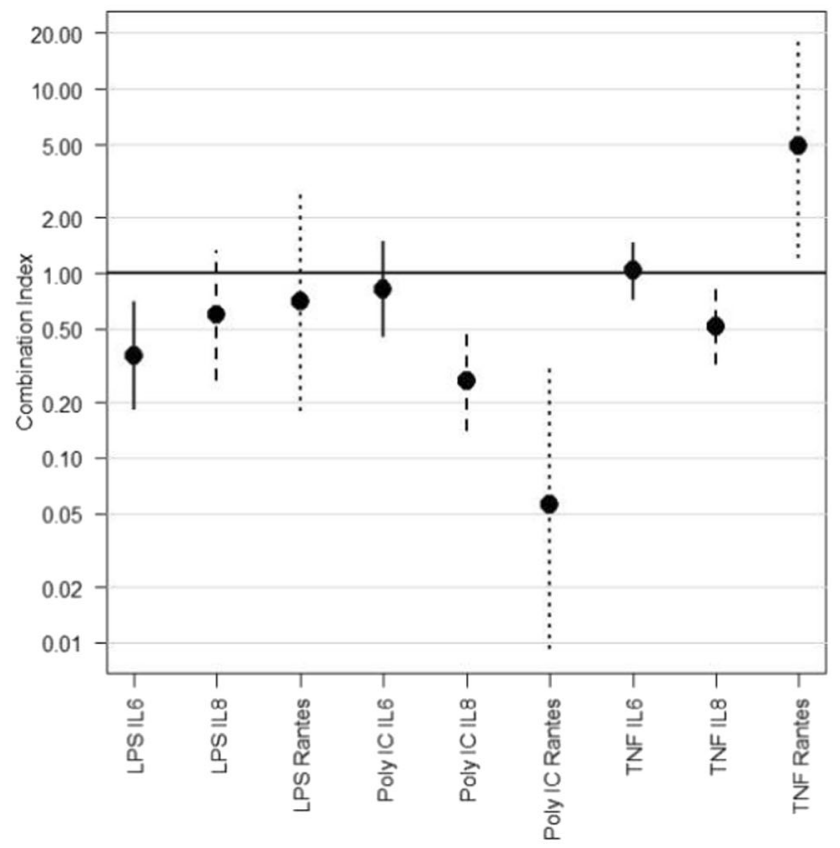

Fig. 2 Combination effect of dexamethasone and BIRB-796: dosesparing and efficacy-enhancing analysis. Dose-sparing analysis to assess whether equivalent responses can be achieved at lower doses of compound than expected given the monotherapy responses (a) and an efficacy-enhancing analysis to assess whether the combination results in a significantly greater maximal effect than either compound as

Dexamethasone $(100 \mathrm{nM})$ significantly induced GILZ and FKBP5 expression above the level of untreated controls $(p<$ 0.05) (Fig. 3d and e). There was no effect of BIRB-796 in combination with dexamethasone.

$\mathrm{TNF} \alpha(10 \mathrm{ng} / \mathrm{ml})$ stimulation or BIRB-796 treatment alone had no effect on GLIZ or FKBP5 expression. Dexamethasone $(100 \mathrm{nM})$ also caused increases in GILZ and FKBP5 expression in TNF $\alpha$ stimulated cells $(p<0.05$ for all comparisons), with the addition of BIRB-796 causing further significant upregulation of GILZ expression compared to corticosteroid alone $(p<0.05$ for all comparisons).

\section{GR nuclear localisation}

The effects of p38 MAPK inhibition on GR cellular location were investigated by Western blot analysis, which confirmed that dexamethasone $(1000 \mathrm{nM})$ significantly reduced GR cytoplasmic protein levels and significantly increased nuclear GR levels compared with untreated controls $(p<0.05$ for both comparisons; Fig. 4). Dexamethasone $(0.1 \mathrm{nM})$ alone and BIRB-796 (1000 nM) alone had no effect on GR levels in either cellular compartment compared with untreated controls. Combining dexamethasone $(0.1 \mathrm{nM})$ with BIRB-796 $(1000 \mathrm{nM})$ reduced cytoplasmic GR and significantly b

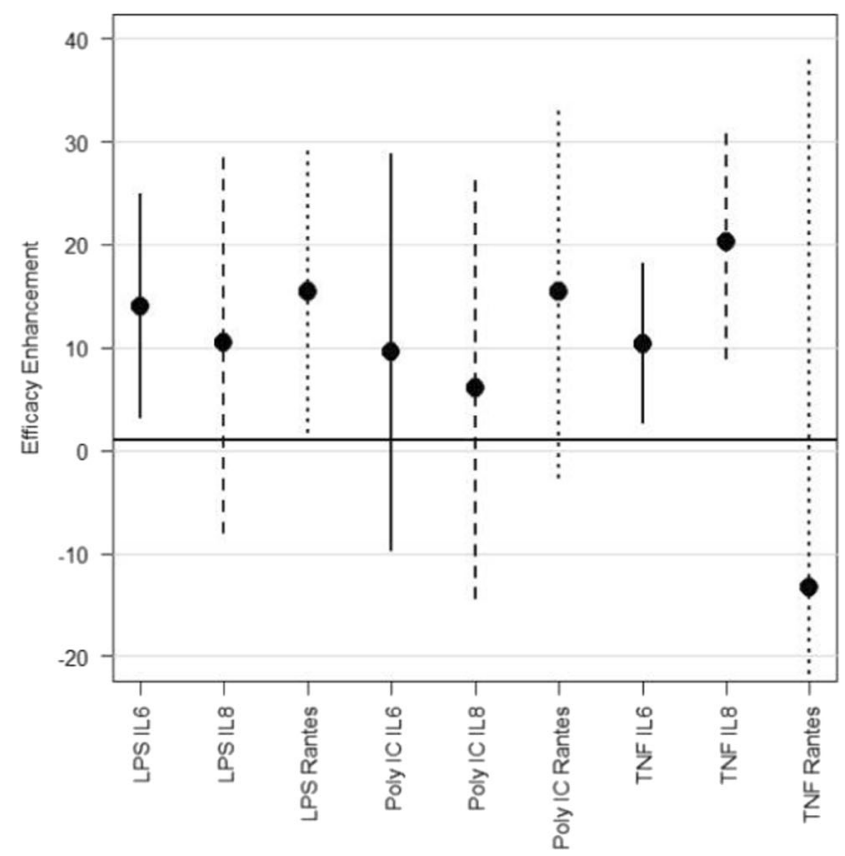

monotherapies (b) were performed. Estimates of the combination index (a) or efficacy-enhancing benefit (b) are plotted with $95 \%$ confidence intervals calculated for each stimulus and cytokine. A combination index of one (a) or efficacy-enhancing benefit of zero (b) corresponds to additivity. Endpoints where the $95 \%$ confidence interval lies completely below one (a) or above zero (b) show statistically significant synergy

increased nuclear GR levels compared with untreated controls ( $p<0.05$ both comparisons) (Fig. 4).

\section{Effects of p38 MAPK inhibition on corticosteroid-induced GR phosphorylation}

The effects of p38 MAPK inhibition on GR phosphorylation status were investigated by Western blot. The phosphorylation of GR S226 and GR S211 by dexamethasone administered alone was confirmed, with a relatively larger increase in GRS211 phosphorylation observed (Fig. 5a and b respectively).

LPS, poly I:C or TNF $\alpha$ caused phosphorylation of p38 MAPK in HBECs, which was inhibited by BIRB-796 but not by dexamethasone (Fig. S5). TNF $\alpha$ was used to further investigate the effects of BIRB-796 inhibition on p38 MAPK and GR phosphorylation. TNF $\alpha$ stimulation for $15 \mathrm{~min}$ significantly increased phosphorylation of p38 MAPK (15$120 \mathrm{~min}$ ) and GR S226 above basal levels but had no effect on GR S211 phosphorylation (Fig. 5c-e). Pre-incubation with BIRB-796 significantly reduced basal and TNF $\alpha$-induced (15-180 min) p38 MAPK phosphorylation. Pre-incubation with BIRB-796 also significantly reduced TNF $\alpha$-induced (15 mins) GR S226 phosphorylation (Fig. 5c and d, respectively) but had no effect on phosphorylated GR S211 levels (Fig. 5e). 


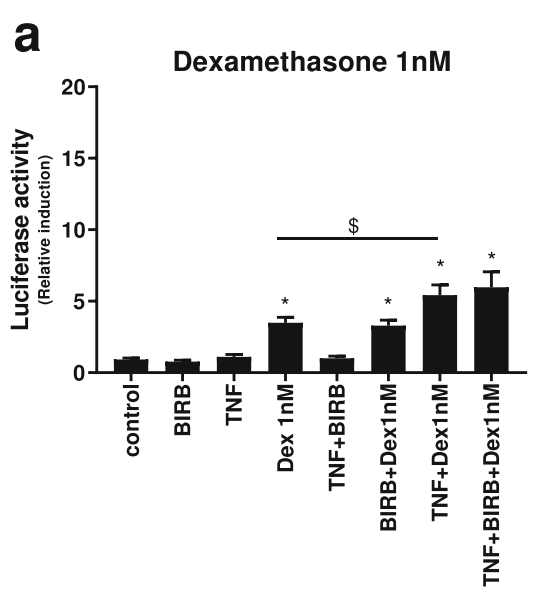

Condition

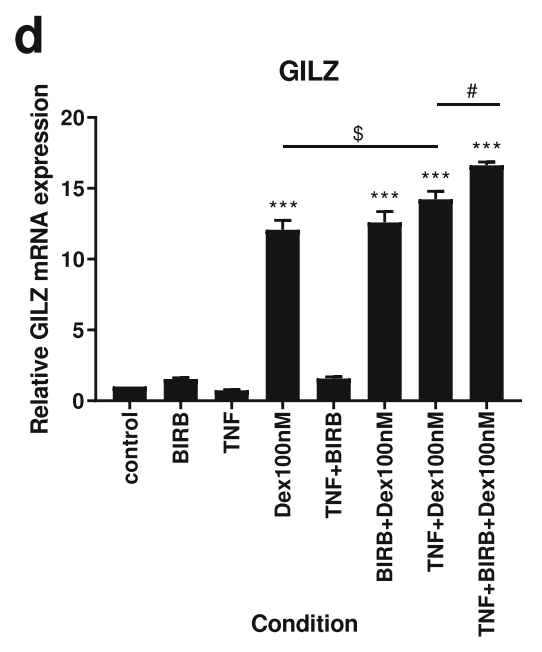

Fig. 3 Effects of p38 MAPK inhibition on dexamethasone-induced GR reporter activity and GR target genes. $16 \mathrm{HBE} 14 \mathrm{o}-$ cells transfected with GR-luciferase reporter (a-c) or left alone (d and e) were stimulated with TNF- $\alpha(10 \mathrm{ng} / \mathrm{ml})$ or left unstimulated followed by treatment with dexamethasone (1-100 nM (a-c, $100 \mathrm{nM}$ d-e), BIRB-796 (1000 nM) alone and in combination with dexamethasone at all concentrations (a-e). GRreporter activity was assessed by luminescence (a-c) or relative

\section{Combination effects of dexamethasone and BIRB-796 in primary bronchial epithelial cells}

Next, we sought to confirm our findings using primary bronchial epithelial cells from both asthma patients and control subjects. Two of the five asthma patients were treated with inhaled corticosteroids. The mean $\mathrm{FEV}_{1}$ was $72.8 \%$ predicted with mean ACQ 1.74, indicating suboptimal asthma control; see Table 1 for demographics.

$\mathrm{TNF} \alpha$ induced a robust cytokine response in HBECs and so was chosen as the stimulus for primary bronchial epithelial cells; TNF $\alpha$ significantly increased secretion of IL- 6 and CXCL8 from both healthy subjects and asthma patients $(p<0.05$ for all comparisons; Fig. 6). Dexamethasone $(100 \mathrm{nM})$ alone and BIRB-796 $(100 \mathrm{nM})$ alone did not significantly inhibit IL-6 release in either asthma patients or controls

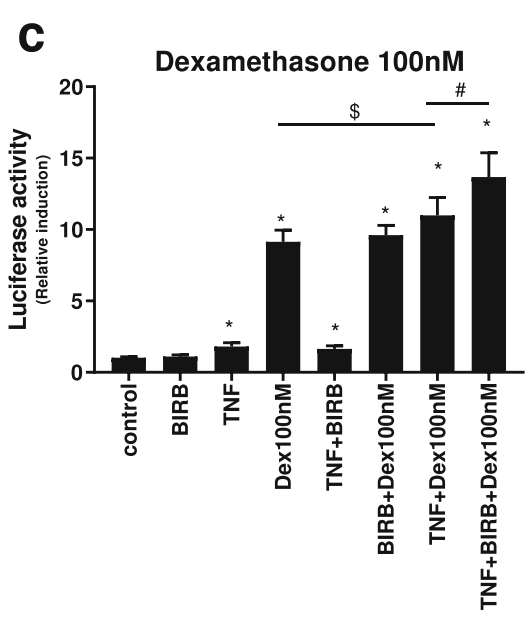

Condition
Condition

FKBP5

expression of GILZ (d) and FKBP5 (e) by real-time q-PCR. Data represent mean \pm SEM of relative activity (a-c), fold change expression (d and e) compared to basal levels from $n=6$ (a-c) or $n=5$ (d and e) experiments. $*, * * *=$ significantly above basal control $(p<0.05$, 0.001). \# = significantly increased above dexamethasone alone in either stimulated or unstimulated cells $(p<0.05) . \$, \$=$ significantly increased above dexamethasone alone in unstimulated cells $(p<0.05,0.01)$

(Fig. 6). Dexamethasone (100 nM) alone significantly inhibited CXCL8 in asthma patients, BIRB-796 (100 nM) alone significantly inhibited CXCL8 in both asthma patients and controls. Dexamethasone in combination with BIRB-796 caused significant inhibition of IL- 6 and CXCL8 in both asthma patients and controls ( $p<0.05$ both comparisons) with inhibition significantly increased above dexamethasone alone in both groups for IL-6 but not CXCL8.

As no differences in drug effects were observed between subject groups (Fig. S6), data were pooled to give additional power for an exploratory IR analysis (Fig. 6c and f). Combination treatment provided significantly greater inhibition of IL-6 than observed with either drug alone $(p<0.05)$. IR calculation for the combination of dexamethasone and BIRB-796 predicted a $34.5 \%$ inhibition of IL- 6 due to additive anti-inflammatory effects, while the observed effect was 
a

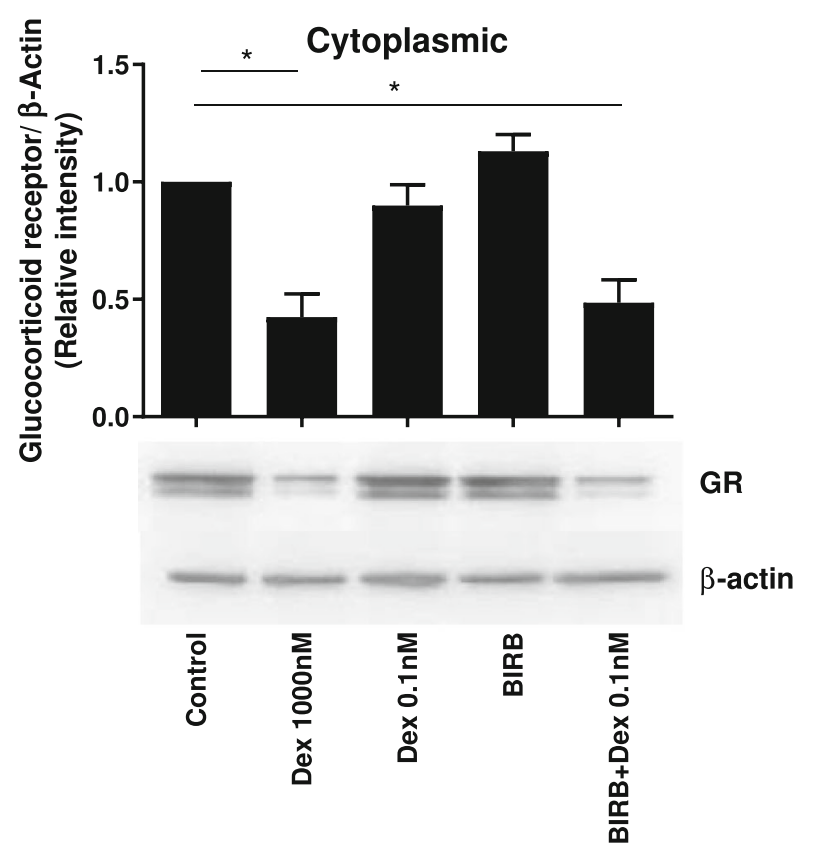

Fig. 4 Effect of BIRB-796 on dexamethasone-induced nuclear localisation of glucocorticoid receptor. $16 \mathrm{HBE} 14 \mathrm{o}^{-}$cells were treated with dexamethasone alone $(0.1$ and $1000 \mathrm{nM})$, BIRB-796 alone $(1000 \mathrm{nM})$ or dexamethasone $(0.1 \mathrm{nM})$ in combination with BIRB-796 $(1000 \mathrm{nM})$. Cytoplasmic (a) and nuclear (b) cellular fractions were obtained and analysed for GR levels by Western blot analysis. Band density

$44.3 \%$ with an IR of 1.28 , falling short of the 1.5 required to demonstrate a synergistic interaction. BIRB-796 alone and in combination with dexamethasone caused significant CXCL8 inhibition that was similar in magnitude.

\section{Expression of phosphorylated p38 MAPK and GR S226 in bronchial epithelium of asthma}

Bronchial biopsies from healthy controls and asthma patients were analysed. Asthma patients were categorized as GINA 1 (no ICS use), GINA 2 (ICS low dose) and GINA 3/4 (ICS plus long-acting beta agonist treatment); demographics are shown in Table 1. The percentage of bronchial epithelial cells positively stained for both phosphorylated p38 MAPK and phosphorylated GR at S226 was significantly higher in GINA 3/4 asthma patients compared with healthy controls $(p<0.05$ both comparisons; Fig. $7 \mathrm{~g}$ and h, respectively) and compared with GINA 1 for GR S226 $(p<0.05)$. There was no significant difference in the percentage of epithelial staining between healthy controls and GINA 1 or GINA 2 for either phosphorylated p38 MAPK or GR. There was also a significant correlation between percentage positive staining for phosphorylated p38 MAPK and GR S226 in the whole study population $\left(R^{2}=0.25, p<0.05\right.$; Fig. $\left.7 \mathrm{i}\right)$.

\section{b}

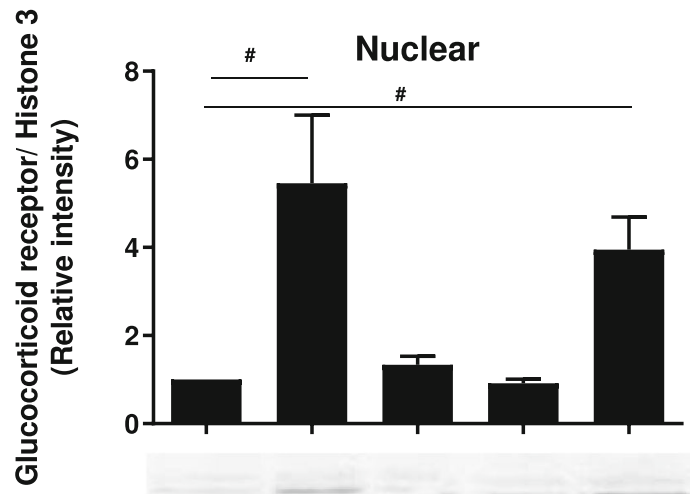

GR

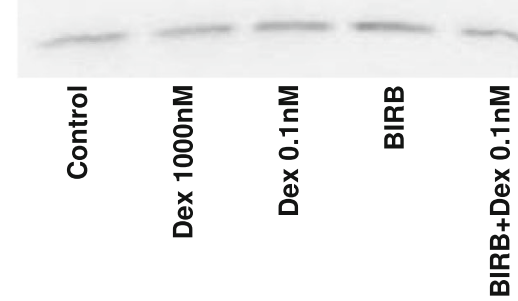

Histone 3

was normalised to $\beta$-actin for cytoplasmic or histone- 3 for nuclear fractions. Representative blots are shown under corresponding conditions. Data presented as mean $\pm \operatorname{SEM}(n=5)$. * = significantly below basal control in cytoplasmic fraction $(p<0.05)$. \# = significantly above basal control in nuclear fraction $(p<0.05)$

\section{Discussion}

Combining a corticosteroid and a p38 MAPK inhibitor in a HBEC line caused increased inhibition of inflammatory mediator release in a synergistic manner for both dose-sparing and efficacy-enhancing effects. This synergy was observed in some, but not all, experimental conditions, varying with the stimulus used and cytokine measured. GR reporter and GR target gene experiments demonstrated an enhancement of GR activity by $\mathrm{p} 38$ MAPK inhibition in TNF $\alpha$-stimulated epithelial cells. Furthermore, p38 MAPK inhibition enhanced corticosteroid-induced GR nuclear localisation. Previous studies have investigated the crosstalk between p38 MAPK and GR function $[8,15,16,19]$, showing that the nature of this crosstalk appears to vary between cell types, but the mechanism of crosstalk in bronchial epithelial cells has not been studied. Focusing on human bronchial epithelial cells, our key findings are that p38 MAPK inhibition enhances GR function, demonstrated through inhibition of inflammatory cytokines, GR reporter activity, GR target gene experiments and GR nuclear localisation.

We observed that $\mathrm{p} 38$ MAPK inhibition reduced TNF $\alpha$ induced phosphorylation of GR at S226 but not S211. We also demonstrated GINA 3/4 asthma patients had higher expression levels of both p38 MAPK and GR S226 
a

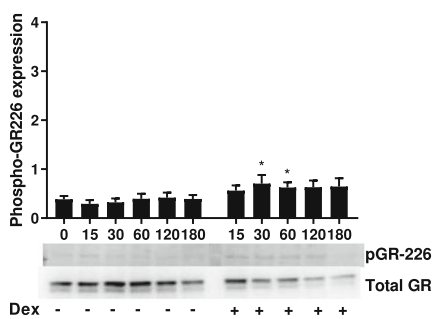

C

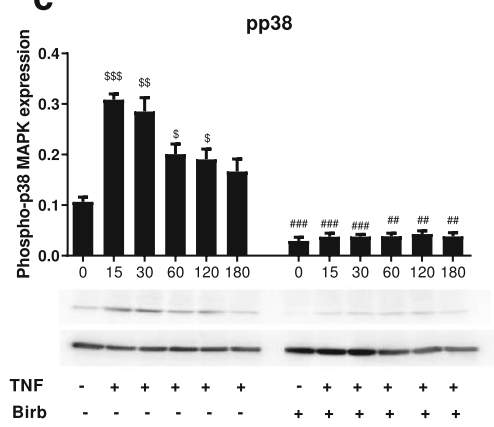

b

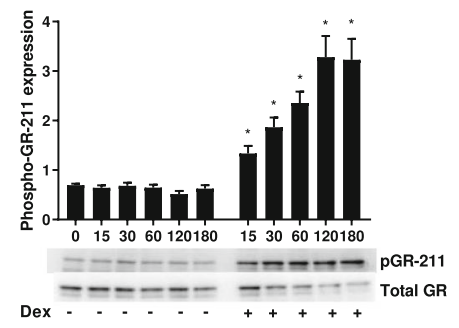

d

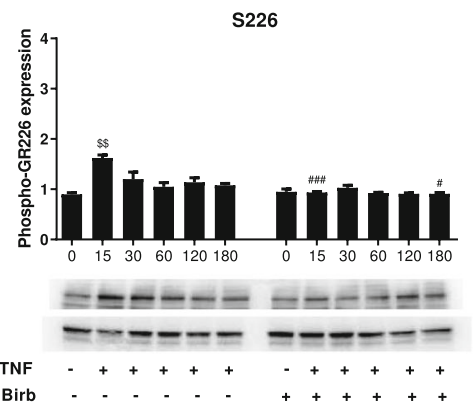

e

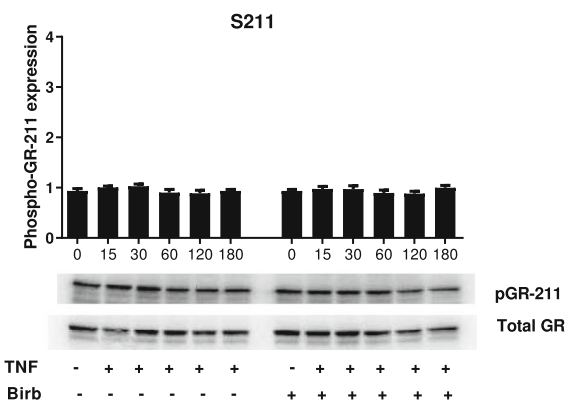

Fig. 5 Effect of dexamethasone or TNF $\alpha$ with/without p38 MAPK inhibition on phosphorylation of p38 MAPK and GR at S226 and S211. $16 \mathrm{HBE} 14 \mathrm{o}-$ cells were stimulated with dexamethasone $(1000 \mathrm{nM})$ alone (a and b) or TNF $\alpha$ with/without BIRB-796 (1000 nM) for 15, 30, 60, 120 and $180 \mathrm{~min}$. Cells were lysed and assessed for phosphorylation of p38 MAPK (c), GR S226 (a and d) or GR S211 (b and e) by Western blotting.
Band density was normalised to total GR $(\mathbf{a}, \mathbf{b}, \mathbf{d}$ and $\mathbf{e})$ or total p38 MAPK (c). Representative blots are shown under corresponding conditions. Data presented as mean $\pm \operatorname{SEM}(n=5)$. $*=$ significantly above time-matched untreated control $(p<0.05) . \$, \$ \$, \$ \$=$ significantly above untreated control $(p<0.05,0.01,0.001)$. \#, \#\#, \#\#\# = significantly below time-matched TNF $\alpha$ only treatment $(p<0.05,0.01,0.001)$ phosphorylation in the bronchial epithelium compared with mild asthma patients and healthy controls. High bronchial epithelial p38 MAPK phosphorylation levels have been previously reported in severe asthma [23]; We have confirmed these findings and show an association with phosphorylated GR S226 expression levels. This association in asthma patients, together with our experiments that demonstrated a role for p38 MAPK in GR S226 phosphorylation, implicates p38 MAPK activation as a mechanism that can modulate GR activity in asthma.

Table 1 Subject demography

\begin{tabular}{|c|c|c|c|c|c|c|c|c|}
\hline \multirow[b]{2}{*}{ Clinical characteristics } & \multicolumn{5}{|c|}{ Immunohistochemistry } & \multicolumn{3}{|c|}{ Bronchial brushes } \\
\hline & Healthy $(n=10)$ & GINA $1(n=5)$ & GINA $2(n=7)$ & GINA 3/4 $(n=6)$ & $p$ value & Healthy $(n=5)$ & Asthma $(n=5)$ & $\mathrm{P}$ value \\
\hline Gender Male/Female & $5 / 5$ & $4 / 1$ & $4 / 3$ & $4 / 6$ & & $4 / 1$ & $4 / 1$ & \\
\hline Age & $27(20-37)$ & $48(41-63)$ & $41(33-68)$ & $39(22-60)$ & $p>0.05$ & $44(40-46)$ & $39(25-65)$ & $\mathrm{p}>0.05$ \\
\hline ICS users & $0 / 10$ & $0 / 6$ & $7 / 7$ & $6 / 6$ & & $0 / 5$ & $2 / 5$ & \\
\hline Daily ICS dose $\mathrm{e}^{\mathrm{a}}$ (mcg) & $0(0)$ & $0(0)$ & $200(0-400)$ & $500(500-2000)$ & $p<0.001$ & $0 \pm 0$ & $300 \pm 141$ & $p<0.01$ \\
\hline LABA users & $0 / 10$ & $0 / 6$ & $0 / 7$ & $6 / 6$ & & $0 / 5$ & $0 / 5$ & \\
\hline Atopy & $0 / 10$ & $4 / 6$ & $4 / 7$ & $4 / 6$ & & $0 / 5$ & $5 / 5$ & \\
\hline $\mathrm{FEV}_{1} \%$ predicted $(\%)$ & $97 \pm 10.4$ & $87.7 \pm 8.9$ & $71.6 \pm 15.4$ & $71.8 \pm 23.6$ & $\mathrm{p}<0.001$ & $110 \pm 9.6$ & $72.8 \pm 11.0$ & $\mathrm{p}<0.001$ \\
\hline Reversibility (mls) & & $273 \pm 145$ & $411 \pm 232$ & $410 \pm 348$ & $\mathrm{p}<0.05$ & $140 \pm 60$ & $682 \pm 438$ & $\mathrm{p}<0.01$ \\
\hline Reversibility (\%) & $4.78 \pm 2.12$ & $9.45 \pm 6.58$ & $19.3 \pm 14.39$ & $21.16 \pm 13.52$ & $\mathrm{p}<0.05$ & $3.48 \pm 1.72$ & $26.0 \pm 18.8$ & $\mathrm{p}<0.01$ \\
\hline ACQ-7 Score & N/A & $0.86 \pm 0.15$ & $1.44 \pm 0.76$ & $2.0 \pm 0.99$ & $p<0.05$ & N/A & $1.74 \pm 0.48$ & \\
\hline
\end{tabular}

Data are presented as means $\pm \mathrm{SD}$, median (range) for age. Asthma control questionnaire (ACQ), forced expiratory volume (FEV), inhaled corticosteroids (ICS), long acting beta agonists (LABA)

${ }^{\text {a }}$ Beclometasone equivalent dose 


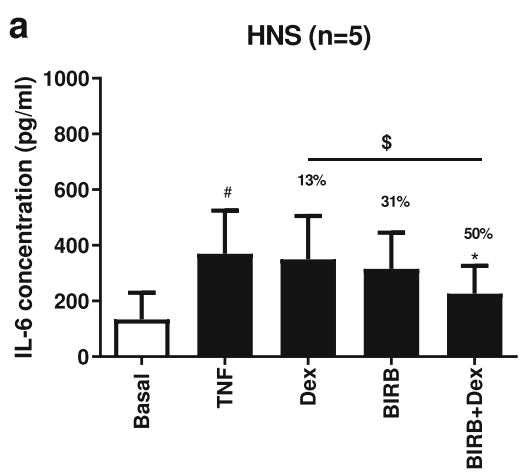

Treatment

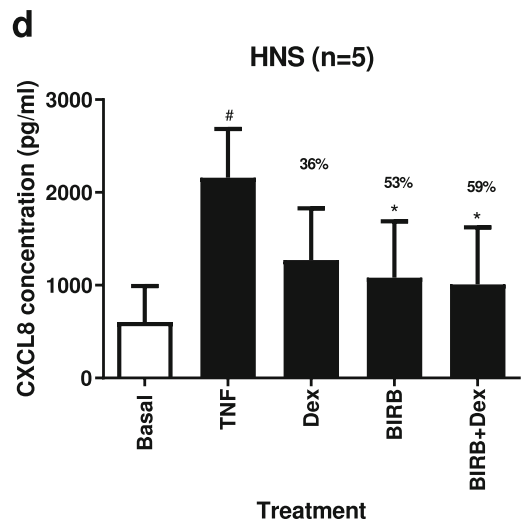

Fig. 6 Combination effect of dexamethasone and BIRB-796 on TNF $\alpha$ induced cytokines in primary human bronchial epithelial cells. Primary bronchial epithelial cells from healthy subjects (HNS) $(n=5)$ or patients with asthma $(n=5)$ were pre-treated with dexamethasone $(100 \mathrm{nM})$ and BIRB-796 (100 nM) alone or in combination or with vehicle (DMSO $0.05 \%)$ for $1 \mathrm{~h}$ before 24 -h stimulation with $\mathrm{TNF} \alpha(10 \mathrm{ng} / \mathrm{ml})$ or media

The downstream implications of the increased phosphorylated p38 MAPK observed in asthma epithelium were investigated by the GR reporter assay and GR target gene experiments to determine the effects of p38 MAPK on GR activity. TNF $\alpha$ stimulation activated p38 MAPK; pharmacological inhibition of this TNF $\alpha$-induced p38 MAPK activation led to enhanced GR activity. This effect was confirmed using different corticosteroids and p38 MAPK inhibitors. While the use of these additional drugs were limited to the GR reporter assay, it would be of interest to investigate their effects in other assays, for example, including the effects of budesonide in combination with a p38 MAPK inhibitor in primary cells. However, our data suggest that the crosstalk observed is a class effect.

Our data show that the GR reporter responds to $\mathrm{TNF} \alpha$ alone. The reporter used is widely accepted as a reporter for GR signalling [28, 29]; however, the promoter can be activated by androgen receptor (AR) as well as glucocorticoid receptor. TNF $\alpha$ can induce AR expression, and there is a crosstalk between NFk $\beta$ and AR signalling at genome level in mammalian cells $[30,31]$. It is possible that the reporter responded to TNF $\alpha$ signalling through AR and not GR. The level of induction of the reporter activity by TNF $\alpha$ alone is however much smaller $(10 \%-15 \%)$ compared to that induced by
Asthma $(n=5)$

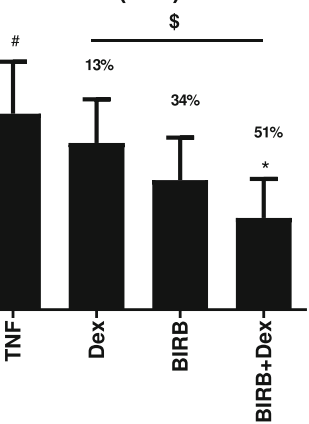

Treatment

Asthma ( $n=4)$

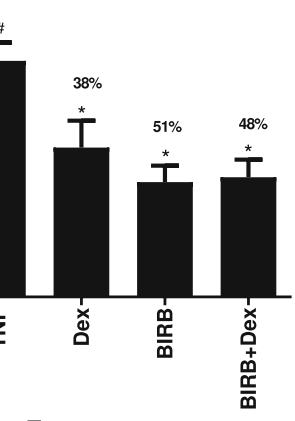

C

Pooled $(n=10)$

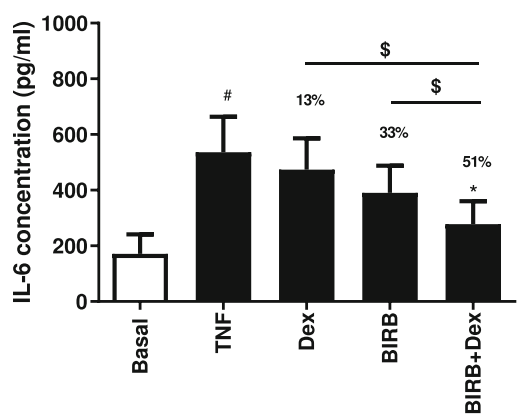

Treatment

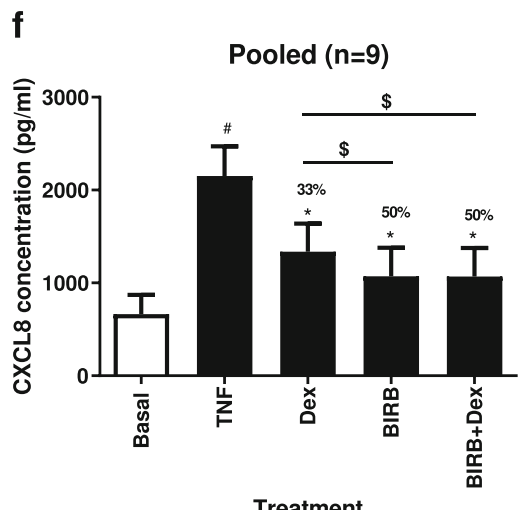

(Basal). Supernatants were collected and assayed for IL-6 (a-c) or CXCL8 (d-f) release by ELISA. Data presented as mean \pm SEM TNF $\alpha$ induced cytokine levels with percentage inhibition shown above each bar. \# = significantly increased above basal levels $(p<0.05) . *=$ significantly below TNF $\alpha$-stimulated vehicle control $(p<0.05)$. $\$=$ significantly increased inhibition above dexamethasone or BIRB-796 alone $(p<0.05)$

dexamethasone (approximately 500\%). Also, we did not observe an increase in the expression of the GR target genes GILZ or FKBP5 above controls in response to TNF $\alpha$ alone.

Corticosteroid and p38 MAPK inhibitor effects on cytokine production from HBECs varied according to the stimulant used and the cytokine measured. Such differences have also been observed in PBMCs and alveolar macrophages [8, $11,32-36]$. This is due to differences in the signalling pathways activated by different stimuli; these pathways may show varying degrees of sensitivity to different drugs. The effects of high corticosteroid concentrations often provided only approximately $50 \%-70 \%$ inhibition of cytokine production. Consistent with our data, other publications, using epithelial cell lines or bronchial epithelial cells obtained by bronchoscopy, have also shown that corticosteroids have either a limited or no effect on inflammatory mediator release [37-39].

In the combination experiments, we frequently observed an additive effect, and the statistical analysis demonstrated a synergistic interaction between the corticosteroid and p38 MAPK inhibitor for some experimental conditions. The use of full dose-response curves allowed analysis of efficacy enhancement and dose-sparing effects to uncover these synergistic effects. This concurs with our previous data in alveolar 

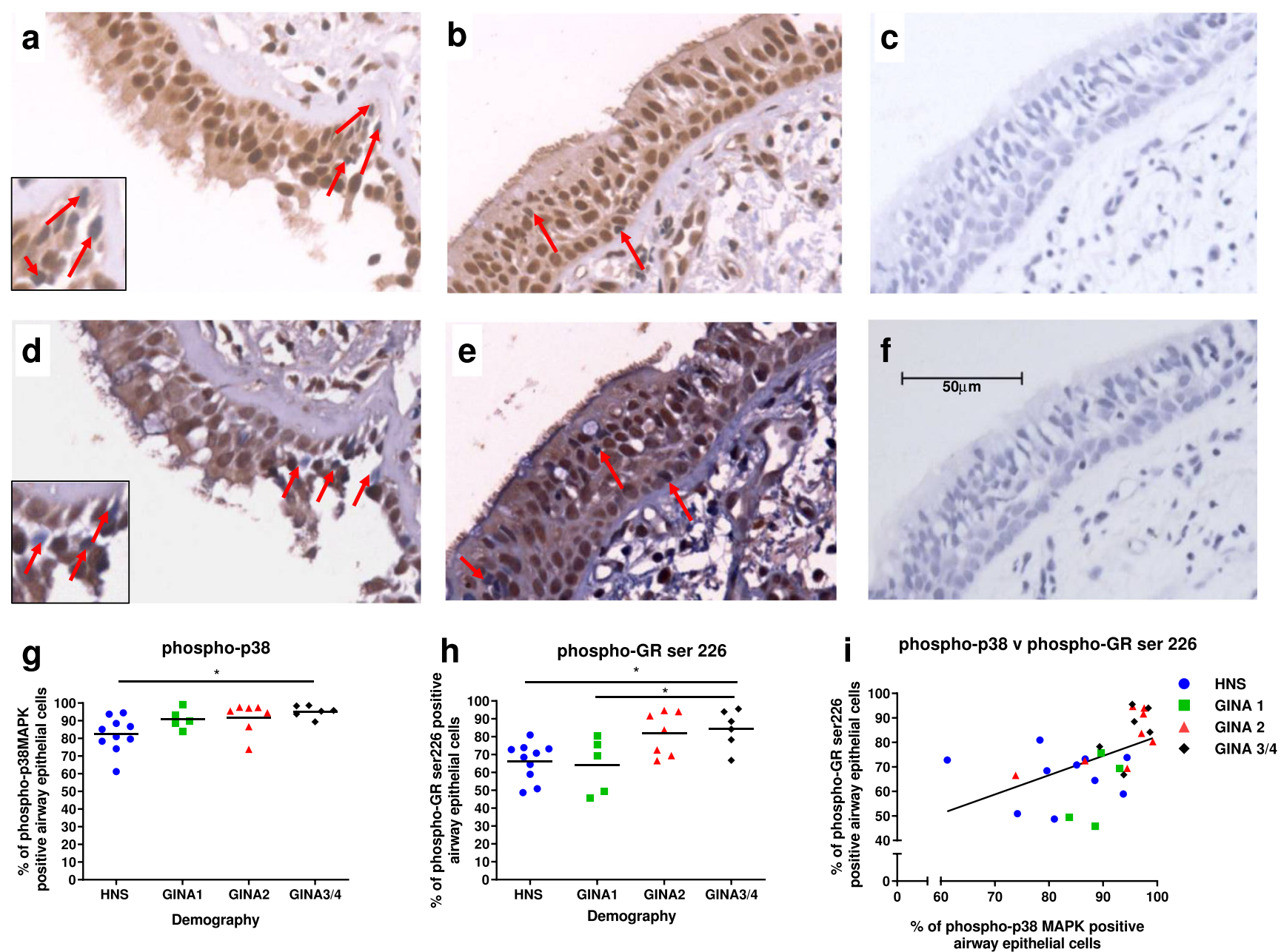

Fig. 7 Expression of phosphorylated p38 MAPK and GR S226 in the bronchial epithelium of patients with asthma and healthy controls. Expression of phosphorylated p38 MAPK and GR at S226 was examined by immunohistochemistry in bronchial biopsy tissue from healthy subjects $(n=10)$ and asthma patients of differing severity (GINA 1, $n=5$; GINA 2, $n=7$; GINA $3 / 4, n=6$ ). Representative images are shown for healthy subjects (HNS) (a and d) and GINA3/4

macrophages from COPD and asthma patients $[8,11]$ and in bronchial epithelial cells [38], showing synergy using full dose-response curves.

An additive anti-inflammatory effect was observed with combination treatment in bronchial epithelial cells obtained by bronchoscopy. The lower cell number availability compared with using a cell line meant that we were unable to construct full dose-response curves, which represent the optimum way to analyse for additive or synergistic interactions $[8$, 11]. This analysis was performed on samples from asthma patients pooled with healthy controls to give additional statistical power. We observed no differences in the drug effects between the two groups, although it has been shown that other cell types from asthma patients can be corticosteroid resistant $[19,21,22]$. It would also be interesting to assess the effects of a p38 MAPK inhibitor on cells from patients with asthma who (b and e) for phospho-p38 MAPK (a and b) and phosphor- GR S226 (d and e), negative controls for p38 MAPK and GR S226 (c and f, respectively). Red arrows indicate negative cells within epithelium. Data presented as positive cells per mm of epithelium for phospho-p38 MAPK (g) and phospho- GR S226 (h) and both (i). Data represents individual patients with mean $(\mathbf{g}$ and $\mathbf{h})$ and linear regression $(\mathbf{i}) . *$ significant between groups $(p<0.05)$

have been treated with ICS compared to steroid naïve asthmatics or healthy controls. The dexamethasone and BIRB-796 concentration used in the primary cells $(100 \mathrm{nM})$ was selected as it was a suboptimal concentration in HBEC experiments on cytokine suppression, thus allowing possible pharmacological addition and synergy to be studied in combination experiments. The primary cells appeared to be less corticosteroid sensitive compared to HBECs, supporting our decision to use a relatively high but suboptimal concentration. Nevertheless, these experiments using cells from asthma patients confirm the potential anti-inflammatory advantages of combining these drug classes, with an additive effect observed on IL-6 production.

While in the present study all inflammatory mediators measured were reduced by glucocorticoids, other studies have shown increased expression of many inflammatory genes 
such as TLR2 or interferon regulatory factor 1 (IRF1) and CXCL10 [40, 41]. Glucocorticoids increase the expression of dual-specificity phosphatase-1 (DUSP1) which targets cJun N-terminal kinase (JNK), extracellular-regulated kinase (ERK) and p38 MAPK pathways induced by inflammatory stimuli to provide feedback inhibition [42]. Glucocorticoids decrease the phosphorylation and activation of $\mathrm{p} 38$ MAPK via DUSP1-dependent regulation in macrophages and epithelial cells [43]. The induction of IRF1 and consequently CXCL10 by glucocorticoids is mediated by the increase of DUSP1 and therefore reduced MAPK activity [41]. In the context of such systems where MAPKs are involved in feedforward regulation, it has been suggested that reduced repression of MAPKs could provide superior repression of inflammatory genes [44].

To further understand the mechanisms of the combination effects observed, we sought to investigate the role p38 MAPK plays on GR phosphorylation at various sites. GR phosphorylation at S211 has an important role in the transcriptional activity of GR [45], by potentially inducing a functionally active folded conformation [46]. A lack of S211 phosphorylation has been linked to glucocorticoid resistance in human lymphoid cells [47]. However, Chang et al. [9] found that GR nuclear localisation was reduced in airway smooth muscle cells from patients with severe asthma compared with healthy controls, but this reduction was not due to altered S211 phosphorylation. In lymphoid cells, S211 is a substrate for p38 MAPK to enhance GR to stimulate transcription [13]. However in alveolar macrophages, exposure to nontypeable Haemophilus influenzae (NTHi) causes p38 MAPKdependent GR phosphorylation at S226 but not S211, resulting in decreased GR function [18]. The role of p38 MAPK activity in the regulation of GR transactivation has also been shown in airway smooth muscle cells via regulation of GR phosphorylation at S203 and S211 [15]. These data highlight potential differences in cell type-specific and stimuli-specific GR phosphorylation.

Phosphorylation of GR S226 is involved with shuttling of GR out of the nucleus [48]. While GR ligands increase phosphorylation of GR at both S211 and S226, it is the relative level of S211 versus S226 phosphorylation which is important. Comparatively, higher phosphorylation at $\mathrm{S} 211$ relative to S226 correlates with GR nuclear localization and greater transcriptional activity and vice versa [17]. We show that, in bronchial epithelial cells, the effect of p38 MAPK is to modulate S226 rather than S211 phosphorylation, which may lead to increased nuclear export of GR.

Our observations regarding GR S226 phosphorylation are supported by data from a study using PBMCs from severe asthma patients, whereby a reduction in GR nuclear translocation was associated with increased GR S226 phosphorylation compared with healthy controls [19]. Furthermore, IL-2 and IL-4 caused p38 MAPK-dependent phosphorylation of GR at S226 in a human monocytic cell line (U937 cells) [19]. Additionally, p38 MAPK inhibition has been shown to reduce phosphorylation of GR S226 induced by NTHi in alveolar macrophages [18] or by IL2/IL-4 in a myeloid cell line [19].

In summary, we have shown molecular crosstalk between p38 MAPK activation and GR function in human bronchial epithelial cells. p38 MAPK inhibitors used in combination with corticosteroids are known to have additive anti-inflammatory effects [8, 11], and we show here the potential for synergistic effects on cytokine production from bronchial epithelial cells. Combining corticosteroids and a p38 MAPK inhibitor may be an effective treatment option in patients with moderate-to-severe asthma, where there is evidence of increased p38 MAPK activation.

Acknowledgments DS and SL are supported by the National Institute for Health Research Manchester Biomedical Research Centre

Author contributions Conception and design, SL, JP, KG and DS; analysis and interpretation, SL, JP, KG, SM, JL, RG, CH and DS; drafting the manuscript for important intellectual content, SL and DS. All authors approved the final version of the manuscript prior to submission.

Funding information This work was partially funded by North West Lung Centre Charity. DS has received sponsorship to attend international meetings, honoraria for lecturing or attending advisory boards and research grants from various pharmaceutical companies including Almirall, AstraZeneca, Boehringer Ingelheim, Chiesi, Genentech, GlaxoSmithKline, Glenmark, Johnson and Johnson, Merck, NAPP, Novartis, Pfizer, Skypharma, Takeda, Teva, Therevance and Verona. $\mathrm{CH}$ is an employee of Roche.

\section{Compliance with ethical standards}

Conflict of interest The authors declare that they have no competing interests.

Open Access This article is licensed under a Creative Commons Attribution 4.0 International License, which permits use, sharing, adaptation, distribution and reproduction in any medium or format, as long as you give appropriate credit to the original author(s) and the source, provide a link to the Creative Commons licence, and indicate if changes were made. The images or other third party material in this article are included in the article's Creative Commons licence, unless indicated otherwise in a credit line to the material. If material is not included in the article's Creative Commons licence and your intended use is not permitted by statutory regulation or exceeds the permitted use, you will need to obtain permission directly from the copyright holder. To view a copy of this licence, visit http://creativecommons.org/licenses/by/4.0/.

\section{References}

1. Price D, Fletcher M, van der Molen T (2014) Asthma control and management in 8,000 European patients: the REcognise asthma and LInk to symptoms and experience (REALISE) survey. NPJ Prim Care Respir Med 24:14009

2. Newton R, Holden NS (2007) Separating transrepression and transactivation: a distressing divorce for the glucocorticoid receptor? Mol Pharmacol 72:799-809 
3. Weigel NL, Moore NL (2007) Steroid receptor phosphorylation: a key modulator of multiple receptor functions. Mol Endocrinol 21: 2311-2319

4. Weikum ER, Knuesel MT, Ortlund EA, Yamamoto KR (2017) Glucocorticoid receptor control of transcription: precision and plasticity via allostery. Nat Rev Mol Cell Biol 18:159-174

5. Saccani S, Pantano S, Natoli G (2002) p38-dependent marking of inflammatory genes for increased NF-kappa B recruitment. Nat Immunol 3:69-75

6. Winzen R, Kracht M, Ritter B, Wilhelm A, Chen CY, Shyu AB, Muller M, Gaestel M, Resch K, Holtmann H (1999) The p38 MAP kinase pathway signals for cytokine-induced mRNA stabilization via MAP kinase-activated protein kinase 2 and an AU-rich regiontargeted mechanism. EMBO J 18:4969-4980

7. Moretto N, Bertolini S, Iadicicco C, Marchini G, Kaur M, Volpi G, Patacchini R, Singh D, Facchinetti F (2012) Cigarette smoke and its component acrolein augment IL-8/CXCL8 mRNA stability via p38 MAPK/MK2 signaling in human pulmonary cells. Am J Physiol Lung Cell Mol Physiol 303:L929-L938

8. Lea S, Harbron C, Khan N, Booth G, Armstrong J, Singh D (2015) Corticosteroid insensitive alveolar macrophages from asthma patients; synergistic interaction with a p38 mitogen-activated protein kinase (MAPK) inhibitor. Br J Clin Pharmacol 79:756-766

9. Chang PJ, Michaeloudes C, Zhu J, Shaikh N, Baker J, Chung KF, Bhavsar PK (2015) Impaired nuclear translocation of the glucocorticoid receptor in corticosteroid-insensitive airway smooth muscle in severe asthma. Am J Respir Crit Care Med 191:54-62

10. Gaffey K, Reynolds S, Plumb J, Kaur M, Singh D (2013) Increased phosphorylated p38 mitogen-activated protein kinase in COPD lungs. Eur Respir J 42:28-41

11. Armstrong J, Harbron C, Lea S, Booth G, Cadden P, Wreggett KA, Singh D (2011) Synergistic effects of p38 mitogen-activated protein kinase inhibition with a corticosteroid in alveolar macrophages from patients with chronic obstructive pulmonary disease. J Pharmacol Exp Ther 338:732-740

12. Irusen E, Matthews JG, Takahashi A, Barnes PJ, Chung KF, Adcock IM (2002) p38 mitogen-activated protein kinase-induced glucocorticoid receptor phosphorylation reduces its activity: role in steroid-insensitive asthma. J Allergy Clin Immunol 109:649-657

13. Miller AL, Webb MS, Copik AJ, Wang Y, Johnson BH, Kumar R, Thompson EB (2005) p38 mitogen-activated protein kinase (MAPK) is a key mediator in glucocorticoid-induced apoptosis of lymphoid cells: correlation between p38 MAPK activation and sitespecific phosphorylation of the human glucocorticoid receptor at serine 211. Mol Endocrinol 19:1569-1583

14. Nader N, Ng SS, Lambrou GI, Pervanidou P, Wang Y, Chrousos GP, Kino T (2010) AMPK regulates metabolic actions of glucocorticoids by phosphorylating the glucocorticoid receptor through p38 MAPK. Mol Endocrinol 24:1748-1764

15. Bouazza B, Debba-Pavard M, Amrani Y, Isaacs L, O'Connell D, Ahamed S, Formella D, Tliba O (2014) Basal p38 mitogenactivated protein kinase regulates unliganded glucocorticoid receptor function in airway smooth muscle cells. Am J Respir Cell Mol Biol 50:301-315

16. Khorasani N, Baker J, Johnson M, Chung KF, Bhavsar PK (2015) Reversal of corticosteroid insensitivity by $\mathrm{p} 38$ MAPK inhibition in peripheral blood mononuclear cells from COPD. Int J Chron Obstruct Pulmon Dis 10:283-291

17. Chen W, Dang T, Blind RD, Wang Z, Cavasotto CN, Hittelman AB, Rogatsky I, Logan SK, Garabedian MJ (2008) Glucocorticoid receptor phosphorylation differentially affects target gene expression. Mol Endocrinol 22:1754-1766

18. Khalaf RM, Lea SR, Metcalfe HJ, Singh D (2017) Mechanisms of corticosteroid insensitivity in COPD alveolar macrophages exposed to NTHi. Respir Res 18:61
19. Mercado N, Hakim A, Kobayashi Y, Meah S, Usmani OS, Chung KF, Barnes PJ, Ito K (2012) Restoration of corticosteroid sensitivity by $\mathrm{p} 38$ mitogen activated protein kinase inhibition in peripheral blood mononuclear cells from severe asthma. PLoS One 7:e41582

20. Loxham M, Davies DE (2017) Phenotypic and genetic aspects of epithelial barrier function in asthmatic patients. J Allergy Clin Immunol 139:1736-1751

21. Chang PJ, Bhavsar PK, Michaeloudes C, Khorasani N, Chung KF (2012) Corticosteroid insensitivity of chemokine expression in airway smooth muscle of patients with severe asthma. J Allergy Clin Immunol 130:877-885 e875

22. Bhavsar P, Hew M, Khorasani N, Torrego A, Barnes PJ, Adcock I, Chung KF (2008) Relative corticosteroid insensitivity of alveolar macrophages in severe asthma compared with non-severe asthma. Thorax 63:784-790

23. Liu W, Liang Q, Balzar S, Wenzel S, Gorska M, Alam R (2008) Cell-specific activation profile of extracellular signal-regulated kinase $1 / 2$, Jun $N$-terminal kinase, and p38 mitogen-activated protein kinases in asthmatic airways. J Allergy Clin Immunol 121:893-902 e892

24. Southworth T, Plumb J, Gupta V, Pearson J, Ramis I, Lehner MD, Miralpeix M, Singh D (2016) Anti-inflammatory potential of PI3Kdelta and JAK inhibitors in asthma patients. Respir Res 17:124

25. Curtis MJ, Bond RA, Spina D, Ahluwalia A, Alexander SP, Giembycz MA, Gilchrist A, Hoyer D, Insel PA, Izzo AA, Lawrence AJ, MacEwan D, Moon LD, Wonnacott S, Weston AH, McGrath J (2015) Experimental design and analysis and their reporting: new guidance for publication in BJP. Br J Pharmacol 172:3461-3471

26. Harbron C (2010) A flexible unified approach to the analysis of preclinical combination studies. Stat Med 29:1746-1756

27. Gisi U, Binder H, Rimbach E (1985) Synergistic interactions of fungicides with different modes of action. T Brit Mycol Soc 85: 299-306

28. Dendoncker K, Timmermans S, Van Looveren K, De Cauwer L, De Bosscher K, Libert C (2017) The nature of the GRE influences the screening for GR-activity enhancing modulators. PLoS One 12: e0181101

29. Dougherty EJ, Elinoff JM, Ferreyra GA, Hou A, Cai R, Sun J, Blaine KP, Wang S, Danner RL (2016) Mineralocorticoid receptor (MR) trans-activation of inflammatory AP-1 signaling: dependence on DNA sequence, MR conformation, and Ap-1 family member expression. J Biol Chem 291:23628-23644

30. Delfino FJ, Boustead JN, Fix C, Walker WH (2003) NF-kappaB and TNF-alpha stimulate androgen receptor expression in sertoli cells. Mol Cell Endocrinol 201:1-12

31. Malinen M, Niskanen EA, Kaikkonen MU, Palvimo JJ (2017) Crosstalk between androgen and pro-inflammatory signaling remodels androgen receptor and NF-kappaB cistrome to reprogram the prostate cancer cell transcriptome. Nucleic Acids Res 45:619630

32. Armstrong J, Sargent C, Singh D (2009) Glucocorticoid sensitivity of lipopolysaccharide-stimulated chronic obstructive pulmonary disease alveolar macrophages. Clin Exp Immunol 158:74-83

33. Kent LM, Smyth LJ, Plumb J, Clayton CL, Fox SM, Ray DW, Farrow SN, Singh D (2009) Inhibition of lipopolysaccharidestimulated chronic obstructive pulmonary disease macrophage inflammatory gene expression by dexamethasone and the p38 mitogen-activated protein kinase inhibitor $\mathrm{N}$-cyano-N'-(2-\{[8-(2, 6-difluorophenyl)-4-(4-fluoro-2-methylphenyl)-7-oxo-7,8dihydropyrido[2,3-d] pyrimidin-2-yl]amino ethyl)guanidine (SB706504). J Pharmacol Exp Ther 328:458-468

34. Lea S, Plumb J, Metcalfe H, Spicer D, Woodman P, Fox JC, Singh D (2013) The effect of PPAR-gamma ligands on in vitro and in vivo models of COPD. Eur Respir J. https://doi.org/10.1183/09031936. 00187812 
35. Southworth T, Metryka A, Lea S, Farrow S, Plumb J, Singh D (2012) IFN-gamma synergistically enhances LPS signalling in alveolar macrophages from COPD patients and controls by corticosteroid-resistant STAT1 activation. Br J Pharmacol 166: 2070-2083

36. Plumb JRL, Lea S, Banyard A, Blaikley J, Ray D, Bizzi A, Volpi G, Facchinetti F, Singh D (2014) Evaluation of glucocorticoid receptor function in COPD lung macrophages using beclomethasone-17monopropionate. PLoS One

37. Woodman LB, Wan WYH, Milone R, Grace K, Sousa A, Williamson R, Brightling CE (2013) Synthetic response of stimulated respiratory epithelium: modulation by prednisolone and $\mathrm{iKK} 2$ inhibition. Chest 143:1656-1666

38. Charron CE, Russell P, Ito K, Lea S, Kizawa Y, Brindley C, Singh D (2017) RV568, a narrow-spectrum kinase inhibitor with p38 MAPK-alpha and -gamma selectivity, suppresses COPD inflammation. Eur Respir J 50. https://doi.org/10.1183/13993003.001882017

39. Higham A, Karur P, Jackson N, Cunoosamy DM, Jansson P, Singh D (2018) Differential anti-inflammatory effects of budesonide and a p38 MAPK inhibitor AZD7624 on COPD pulmonary cells. Int J Chron Obstruct Pulmon Dis 13:1279-1288

40. Sakai A, Han J, Cato AC, Akira S, Li JD (2004) Glucocorticoids synergize with IL-1beta to induce TLR2 expression via MAP kinase Phosphatase-1-dependent dual inhibition of MAPK JNK and p38 in epithelial cells. BMC Mol Biol 5:2

41. Shah S, King EM, Mostafa MM, Altonsy MO, Newton R (2016) DUSP1 maintains IRF1 and leads to increased expression of IRF1dependent genes: a MECHANISM PROMOTING
GLUCOCORTICOID INSENSITIVITY. J Biol Chem 291: 21802-21816

42. Arthur JS, Ley SC (2013) Mitogen-activated protein kinases in innate immunity. Nat Rev Immunol 13:679-692

43. Clark AR, Martins JR, Tchen CR (2008) Role of dual specificity phosphatases in biological responses to glucocorticoids. J Biol Chem 283:25765-25769

44. Newton R, Shah S, Altonsy MO, Gerber AN (2017) Glucocorticoid and cytokine crosstalk: feedback, feedforward, and co-regulatory interactions determine repression or resistance. J Biol Chem 292: 7163-7172

45. Wang Z, Frederick J, Garabedian MJ (2002) Deciphering the phosphorylation "code" of the glucocorticoid receptor in vivo. J Biol Chem 277:26573-26580

46. Garza AM, Khan SH, Kumar R (2010) Site-specific phosphorylation induces functionally active conformation in the intrinsically disordered $\mathrm{N}$-terminal activation function (AF1) domain of the glucocorticoid receptor. Mol Cell Biol 30:220-230

47. Miller AL, Garza AS, Johnson BH, Thompson EB (2007) Pathway interactions between MAPKs, mTOR, PKA, and the glucocorticoid receptor in lymphoid cells. Cancer Cell Int 7:3

48. Itoh M, Adachi M, Yasui H, Takekawa M, Tanaka H, Imai K (2002) Nuclear export of glucocorticoid receptor is enhanced by c-Jun Nterminal kinase-mediated phosphorylation. Mol Endocrinol 16: $2382-2392$

Publisher's note Springer Nature remains neutral with regard to jurisdictional claims in published maps and institutional affiliations. 